\begin{tabular}{ll|l} 
Case Reports in & \multicolumn{2}{c}{ Case Rep Gastroenterol 2013;7:363-368 } \\
\cline { 2 - 3 } Gastroenterology & $\begin{array}{l}\text { DOI: 10.1159/000355161 } \\
\text { Publisnea onine: September 3, 2013 }\end{array}$ & $\begin{array}{l}\text { ○ 2013 S. Karger AG, Basel } \\
\text { www.karger.com/crg }\end{array}$ \\
\hline & $\begin{array}{l}\text { This is an Open Access article licensed under the terms of the Creative Commons } \\
\text { Attribution-NonCommercial 3.0 Unported license (CC BY-NC) (www.karger.com/OA- } \\
\text { license), applicable to the online version of the article only. Distribution permitted for non- } \\
\text { commercial purposes only. }\end{array}$
\end{tabular}

\title{
Induction of Eosinophilic Esophagitis by Sublingual Pollen Immunotherapy
}

\author{
Stephan Miehlke ${ }^{a} \quad$ Oral Alpan $^{c}$ Sören Schröder ${ }^{b} \quad$ Alex Straumann $^{d}$ \\ ${ }^{a}$ Center for Digestive Diseases, Cooperation of Internal Medicine, and ${ }^{b}$ Institute \\ for Pathology Lademannbogen, Hamburg, Germany; ${ }^{\circ}$ O\&O ALPAN, Section on \\ Immunopathogenesis, Fairfax, Va., USA; ${ }^{d}$ Swiss EoE Research Network, Olten, Switzerland
}

\section{Key Words}

Dysphagia · Eosinophilic esophagitis · Food allergy · Pollen allergy · Sublingual immunotherapy

\begin{abstract}
Sublingual immunotherapy (SLIT) is increasingly investigated and utilized for the treatment of food and pollen allergies. Previous case reports suggested that eosinophilic esophagitis (EoE) might develop as a long-term complication in children after completion of oral immunotherapy. Here, we describe a 44-year-old female with a medical history of pollinosis who for the first time in her life developed complete manifestation of EoE (peak eosinophils 164/high power field) 4 weeks after initiation of SLIT using specific soluble allergens (hazelnut, birch, alder) according to previous specific serum IgE testing. After discontinuation of SLIT, EoE resolved completely within 4 weeks without any other medical intervention. During a follow-up of 12 months the patient remained free of any esophageal symptoms. This is the first case report demonstrating a close and therefore likely causative association between pollen SLIT and EoE in an adult patient.

(c) 2013 S. Karger AG, Basel
\end{abstract}

\section{Introduction}

Sublingual immunotherapy (SLIT) is increasingly investigated and utilized for the treatment of food and pollen allergies. While SLIT is generally considered to be safe, a recent meta-analysis of randomized controlled trials has identified limitations in the standardization of adverse events [1]. Previous case reports suggested that eosinophilic esophagitis (EoE) might develop as a long-term complication in children several months after comple-

Stephan Miehlke MD

Center for Digestive Diseases

Eppendorfer Landstrasse 42

DE-20249 Hamburg (Germany)

E-Mail prof.miehlke@mdz-hamburg.de 
Miehlke et al.: Induction of Eosinophilic Esophagitis by Sublingual Pollen Immunotherapy

tion of milk or egg oral immunotherapy [2,3]. Currently it is unknown whether EoE may also occur in adults undergoing SLIT and whether this might also happen as a consequence of pollen SLIT. Here we describe an adult female who developed EoE during ongoing SLIT for pollen allergy.

\section{Case Report}

A 44-year-old female presented at our center with increasing dysphagia for 4 weeks. At the time of presentation, she reported having dysphagia for the first time in her life which occurred every day. Prior to this episode, the patient had never experienced any esophageal symptoms. Difficulties with swallowing required her to adapt her eating habits such as drinking liquids after swallowing food (dysphagia score 7 on a scale from 0 to 9). Her medical history revealed pollinosis since childhood and additional allergic asthma at the age of 22 years which improved for several years after subcutaneous immunotherapy. A deterioration occurred at the age of 42 years. At this time a total serum IgG of $757 \mathrm{U} / \mathrm{ml}$ was documented. Prick testing and specific serum IgE identified grass, rye, hazelnut, birch alder and oak as major allergens. Her family history was positive for pollinosis (mother and brother).

Four weeks before the onset of dysphagia, the patient had begun SLIT with ORALVAC Compact (Bencard Allergie GmbH, Munich, Germany), a commercially available treatment considered to be safe [4]. The SLIT contained specific soluble allergens (hazelnut, birch, alder) according to previous specific serum IgE testing, administered sublingually as prescribed by the manufacturer's instructions. Upper endoscopy showed confluent whitish exudates and longitudinal red furrows in the proximal and the distal esophagus (fig. 1a). Biopsies from these lesions revealed a predominantly eosinophilic inflammation with a peak infiltration of 164 eosinophils per high power field (fig. 1b), which confirmed the diagnosis of EoE. Immediately after upper endoscopy, the patient discontinued SLIT, which led to complete resolution of dysphagia within 4 weeks without any other medical intervention. A follow-up endoscopy 4 weeks after withdrawal of SLIT demonstrated a macroscopically normal esophagus (fig. 2a). Biopsies from the proximal and distal esophagus revealed normal mucosa without any eosinophilic inflammation (fig. 2b). During a follow-up of 12 months the patient remained free of any esophageal symptoms.

\section{Discussion}

This is the first case report demonstrating a close and therefore likely causative association between pollen SLIT and EoE in an adult patient. The clinical course together with all findings is highly suggestive of SLIT as the causative factor for EoE in this patient. The final proof that SLIT was the trigger for EoE would require re-exposition with confirmation of relapse. We did not perform this procedure due to ethical considerations. Our patient developed a complete manifestation of EoE about 4 weeks after initiation of SLIT using hazelnut, birch and alder, which are typically airborne antigens. According to the manufacturer's description, dysphagia appears to be a rare but well-recognized side effect of SLIT. The incidence and the exact cause of dysphagia during SLIT, however, are currently unknown. Therefore, we hypothesize that SLIT may be a potential trigger for EoE due to high antigen exposure of the esophagus in predisposed individuals.

EoE is a chronic inflammatory, immune/antigen-mediated esophageal disease increasingly recognized during the last decade [5]. Although the common belief is that EoE is pri- 
Miehlke et al.: Induction of Eosinophilic Esophagitis by Sublingual Pollen Immunotherapy

marily a food allergen-triggered disease, several lines of evidence suggest that both airborne and food allergens may be involved in the etiology of EoE. For example, a seasonal and geographical pattern of EoE which may be compatible with increased airborne allergen exposure has been described [6, 7]. On the other hand, a recent prospective study in adults with EoE confirmed previous observations that a six-food elimination diet significantly improved both endoscopic and histological features of EoE and its symptoms [8]. Furthermore, reintroduction of the individual food components resulted in recurrence of EoE, with wheat and milk being the most frequent causes. Finally, several cases of de novo EoE following high-volume exposure of aeroallergens has recently been reported [9].

The immunological effects induced by allergens introduced through the mouth are quite variable and depend on the dose and type of the allergen, low doses inducing immune deviation and high doses resulting in deletion of antigen-specific T cells $[10,11]$. Since the present literature on SLIT indicates a shift in the immune response resulting in regulatory T cells [12], we can assume that the concentrations of allergens that are used in therapy do not result in deletion of allergen-specific T cells as seen in high-dose oral tolerance. In some cases, while reducing allergen-specific IgE levels, sublingually administered pollen extracts induced IL-10, IL-5 and Foxp3 expression T cells [13]. Since IL-5 is a key mediator in eosinophil activation, such immunological effects of SLIT can result in EoE. Even though EoE has not been reported previously in subjects undergoing SLIT, there are several reasons that we believe may have influenced this. First, most SLIT studies have been done in adults, and the symptoms of EoE in this population can be very subtle (such as altered feeding behavior), and the questionnaires of SLIT protocols do not address this question [5]. Second, the time of induction of an eosinophilic disease can be much longer than what it takes to develop an IgEmediated allergy. Most IgE-mediated food allergies present in the pediatric age group as opposed to EoE, which can present in all age groups [5]. It is possible that it may take many years from the time sensitization starts to becoming clinically symptomatic, hence the EoE side effects of SLIT may not become evident many years later. Finally, the frequent occurrence of abdominal symptoms in patients receiving oral immunotherapy for desensitization for foods such as milk and egg [2,3] suggests the possibility of eosinophilic gastrointestinal disease, but this has not been addressed systematically.

Our case report, in conjunction with similar recently published cases, suggests that both food and pollen SLIT could be a trigger for EoE in predisposed individuals. Giving the strongly rising incidence of EoE [14], physicians evaluating patients with dysphagia, e.g. gastroenterologists and otolaryngologists, should be aware of this potential and clinically relevant complication of SLIT and consider it in patient care and follow-up. Furthermore, EoE-specific questionnaires should be incorporated into clinical trials involving allergens introduced orally or sublingually, and proper endoscopic assessments should be implemented in symptomatic individuals.

\section{References}

1 Lin SY, Erekosima N, Kim JM, Ramanathan M, Suarez-Cuervo C, Chelladurai Y, Ward D, Segal JB: Sublingual immunotherapy for the treatment of allergic rhinoconjunctivitis and asthma: a systematic review. JAMA 2013;309:1278-1288.

-2 Sánchez-García S, Rodríguez Del Río P, Escudero C, Martínez-Gómez MJ, Ibáñez MD: Possible eosinophilic esophagitis induced by milk oral immunotherapy. J Allergy Clin Immunol 2012;129:1155-1157.

-3 Ridolo E, De Angelis GL, Dall'aglio P: Eosinophilic esophagitis after specific oral tolerance induction for egg protein. Ann Allergy Asthma Immunol 2011;106:73-74.

4 Drachenberg KJ, Urban E, Proll S, Woroniecki SR: Sublingual specific immunotherapy for adults and children: a post-marketing surveillance study. Allergol Immunopathol 2004;32:76-81. 
Miehlke et al:. Induction of Eosinophilic Esophagitis by Sublingual Pollen Immunotherapy

5 Liacouras CA, Furuta GT, Hirano I, Atkins D, Attwood SE, Bonis PA, et al: Eosinophilic esophagitis: Updated consensus recommendations for children and adults. J Allergy Clin Immunol 2011;128:3-20.

-6 Moawad FJ, Veerappan GR, Lake JM, Maydonovitch CL, Haymore BR, Kosisky SE, Wong RK: Correlation between eosinophilic oesophagitis and aeroallergens. Aliment Pharmacol Ther 2010;31:509-515.

7 Hurrell JM, Genta RM, Dellon ES: Prevalence of esophageal eosinophilia varies by climate zone in the United States. Am J Gastroenterol 2012;107:698-706.

-8 Gonsalves N, Yang GY, Doerfler B, Ritz S, Ditto AM, Hirano I: Elimination diet effectively treats eosinophilic esophagitis in adults; food reintroduction identifies causative factors. Gastroenterology 2012;142:14511459.

-9 Wolf WA, Jerath MR, Dellon ES: De-novo onset of eosinophilic esophagitis after large volume allergen exposures. J Gastrointestin Liver Dis 2013;22:205-208.

10 Chen Y, Inobe J, Marks R, Gonnella P, Kuchroo VK, Weiner HL: Peripheral deletion of antigen-reactive T cells in oral tolerance. Nature 1995;376:177-180.

11 van Wilsem EJ, Breve J, Savelkoul H, Claessen A, Scheper RJ, Kraal G: Oral tolerance is determined at the level of draining lymph nodes. Immunobiology 1995;194:403-414.

12 Akdis CA, Barlan IB, Bahceciler N, Akdis M: Immunological mechanisms of sublingual immunotherapy. Allergy 2006;61(suppl 81):11-14.

-13 Geroldinger-Simic M, Kinaciyan T, Nagl B, Baumgartner-Durchschlag U, Huber H, Ebner C, Lidholm J, Bartel D, Vieths S, Jahn-Schmid B, Bohle B: Oral exposure to Mal d 1 affects the immune response in patients with birch pollen allergy. J Allergy Clin Immunol 2013;131:94-102.

14 Syed AA, Andrews CN, Shaffer E, Urbanski SJ, Beck P, Storr M: The rising incidence of eosinophilic oesophagitis is associated with increasing biopsy rates: a population-based study. Aliment Pharmacol Ther 2012;36:950-958. 
Miehlke et al: Induction of Eosinophilic Esophagitis by Sublingual Pollen Immunotherapy
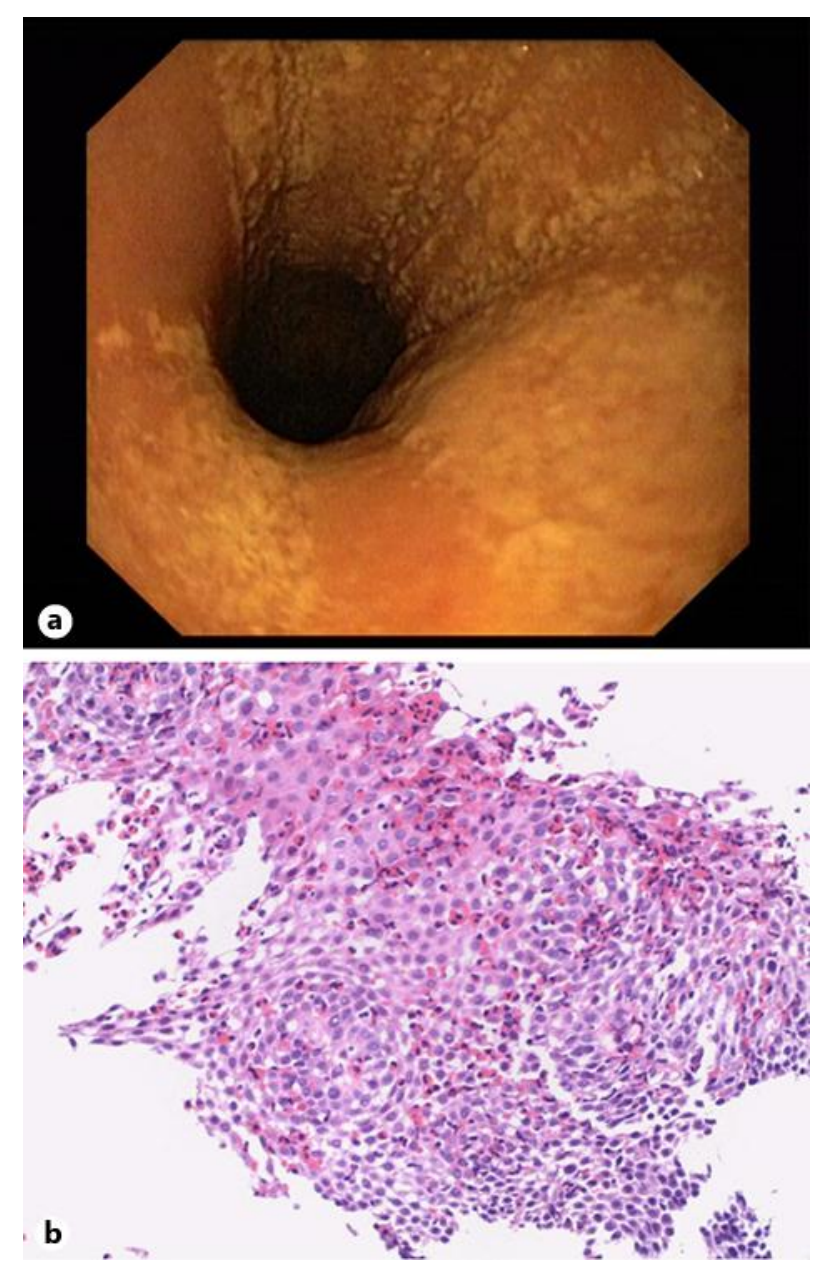

Fig. 1. Endoscopic (a) and histological findings (b) 4 weeks after initiation of SLIT. b Hematoxylin \& eosin staining, magnification $\times 150$. 
Case Reports in
Gastroenterology

\begin{tabular}{l|l}
\hline Case Rep Gastroenterol 2013;7:363-368 \\
\hline DOI: 10.1159/000355161 & $\begin{array}{l}\text { ○ 2013 S. Karger AG, Basel } \\
\text { www.karger.com/crg }\end{array}$ \\
\hline
\end{tabular}

Miehlke et al.: Induction of Eosinophilic Esophagitis by Sublingual Pollen Immunotherapy
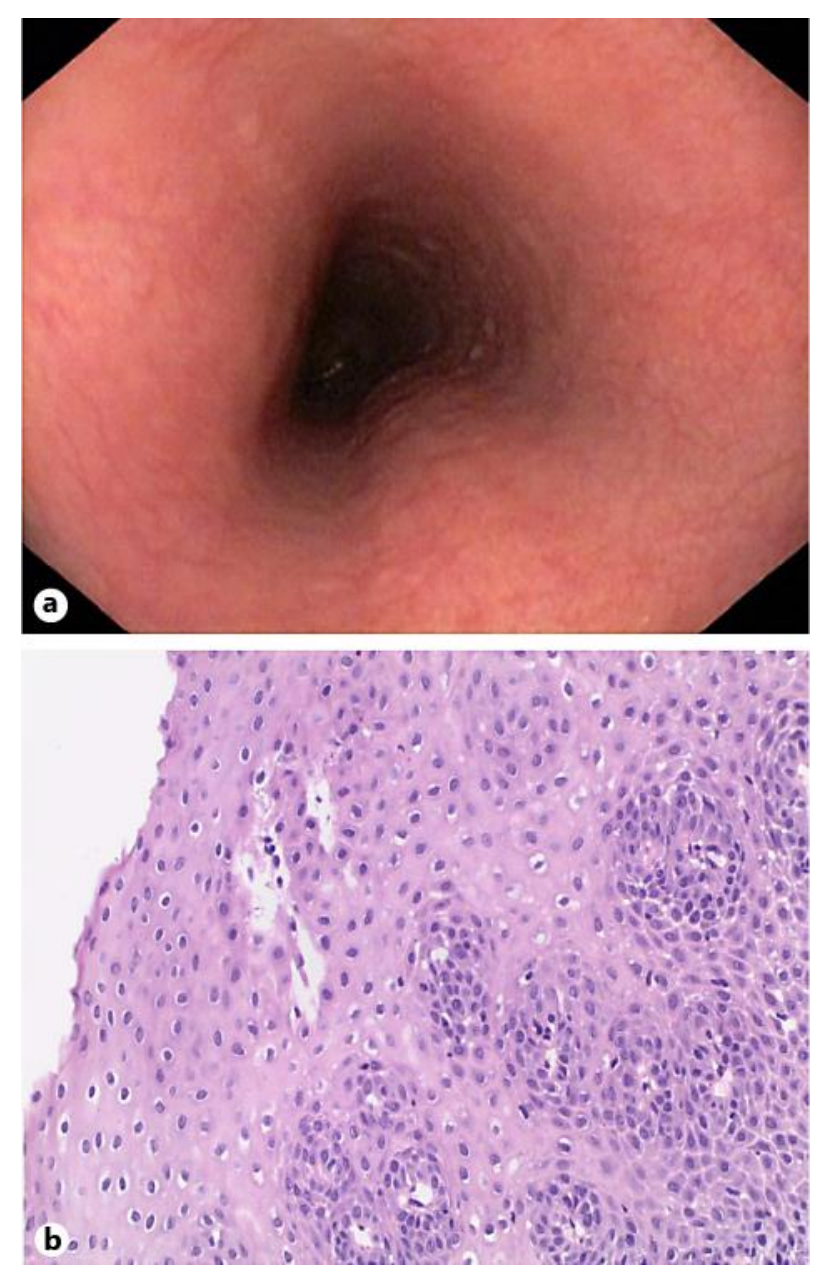

Fig. 2. Endoscopic (a) and histological findings (b) 4 weeks after withdrawal of SLIT. b Hematoxylin \& eosin staining, magnification $\times 150$. 